Lapeña Gallego, Gloria.

Investigadora Predoctoral, Universidad de Murcia, Departamento de Bellas Artes,

Grupo de Investigación Arte y Políticas de Identidad.

Ortuño Mengual, Pedro.

Profesor Titular, Universidad de Murcia, Departamento de Bellas Artes,

Grupo de Investigación Arte y Políticas de Identidad.

\title{
El archivo de historias en la construcción de la Historia: la obra cartográfica de Rogelio López Cuenca.
}

\section{The archive of stories in the configuration of History: the Rogelio López Cuenca's cartographic project.}

\author{
TIPO DE TRABAJO: \\ Comunicación virtual.
}

PALABRAS CLAVE:

Rogelio López Cuenca; Historia; Memoria; Cartografía; Ciudad.

KEY WORDS:

Rogelio López Cuenca; History; Memory; Cartography; City.

RESUMEN.

A partir de los años setenta, los historiadores han acercado sus investigaciones a las necesidades de una sociedad plural. El artista contemporáneo se hace eco de estos nuevos enfoques y adopta una postura crítica ante el desigual tratamiento de las diversas identidades a lo largo de una Historia más o menos reciente. Uno de los recursos para hacer frente al olvido es el de poner en evidencia la huella como reducto que permanece en el espacio físico, vinculado emocionalmente a las sociedades que la generaron. Algunos artistas asumen el papel de historiadores y crean archivos abiertos a partir de historias locales al margen de la Historia institucional, si bien ambas comparten los mismos espacios. En este sentido, la obra cartográfica del artista malagueño Rogelio López Cuenca se basa en la creación de archivos de Memorias individuales de ciudades para configurar una Memoria colectiva oculta, omitida o tergiversada. El revés de la trama, surgido del taller Derrotas alternativas: Now/here Mataró (2008); Mappa di Roma (Roma, 2006-07); No/w/here. Ciudad de México (México, 2010); y Polivalencias (Valencia 2015-16), son proyectos dirigidos por este artista sobre las memorias locales de los habitantes de la ciudad, recogidas mediante una labor de investigación rigurosa, y siguiendo un proceso historiográfico y de mapeo. El resultado final, materializado en forma de cartografía digital interactiva, constituye un archivo de historias de diversas temporalidades reflejadas a manera de hipertexto, y que tratan temas latentes que forman parte del presente de las ciudades.

ABSTRACT.

From the seventies, the historians have brought their research closer to the needs of a plural society. The artist, too, adopts a critical stance against the unequal treatment of the various identities throughout a more or less recent History. One way to deal with oblivion is to evidence the trace as a redoubt present in physical space, emotionally linked to the societies that generated it. Some contemporary artists assume the role of historians and they create archives open from local histories in 
the margins of institutional History, although both share the same spaces. In this sense, the cartographic projects of the artist Rogelio López Cuenca (Málaga, Spain, 1959) are based on the creation of archives of individual memories of cities to set up a hidden, omitted or distorted collective memory. El revés de la trama is an alternative cartographic project originated from the Derrotas alternativas: Now/here Mataró (2008); Mappa di Roma (Rome, 2006-07); No/w/here. Ciudad de México (México, 2010); and Polivalencias (Valencia 2015-16), are projects directed by this artist about citizen memories local which he collects through a rigorous research work following a historiography and cartography method. The conclusion, materialized under the formal structure of interactive map in its web page, is a file of histories of diverse temporalities in hypertext that speak of latent topics still present in the cities to be part of its present.

Este trabajo de investigación forma parte de la Tesis Doctoral financiada con una ayuda predoctoral (19099/FPI/13) con cargo al Programa de Formación del Personal Investigador de la Fundación Séneca, Agencia de Ciencia y Tecnología de la Región de Murcia en el marco del III PCTRM 2011-14.

\section{CONTENIDO.}

Introducción.

El estudio de las Ciencias Humanas y Sociales, entendidas como aquellas que abarcan el comportamiento del hombre en la sociedad y sus formas de organización, ha dado lugar a una literatura científica que ha ido configurando el método de estudio de diferentes disciplinas autónomas. Algunas de las ciencias pertenecientes a este ámbito, como la Historia, investigan la evolución de las sociedades en distintas temporalidades, utilizando fuentes documentales escritas, así como huellas materiales que permanecen más o menos conservadas en el espacio urbano. Tradicionalmente, la Historia hegemónica o institucional ha estado sujeta a censura u omisión de los grupos sociales marginados u oprimidos, con el fin de justificar de algún modo las actuaciones de los gobiernos opresores que, por otra parte, se perpetúan mediante el monumento como principal Patrimonio material.

A partir de los años setenta, la escritura de la Historia o Historiografía experimenta un giro importante. Se elaboran leyes memoriales que dan cabida al tratamiento de colectivos silenciados como forma de hacer frente al olvido. Todas estas identidades heterogéneas, como las de género, migrantes, las de grupos pertenecientes a religiones o creencias no oficiales, se sitúan en espacios concretos que, en el caso de las ciudades, dan lugar a una superposición de estratos horizontales a manera de hojas de un libro, con una importante información y fuente de trabajo para la Historia.

En este contexto, el artista contemporáneo asume el papel de historiador centrado en prácticas relacionadas con los procesos de construcción, materialización y transmisión de la memoria de colectivos no hegemónicos a partir de memorias individuales o recuerdos. Recupera documentos y objetos para mostrar las historias no contadas, paralelas al acontecimiento histórico y al monumento, contribuyendo así a la labor crítica y justa de visibilizar historias omitidas u olvidadas por la Historia oficial.

En el presente trabajo nos ocupamos de estas formas de narración de la Historia a base de retazos de historias concretas en las que el artista trabaja en los márgenes, creando archivos que recogen las memorias de los distintos colectivos que habitan la ciudad. Para ello tomamos como ejemplo la obra cartográfica constituida por cuatro proyectos de naturaleza archivística del artista malagueño Rogelio López Cuenca, y comparamos el proceso creativo con el propio de la Historiografía y la ciencia cartográfica. Comenzamos con una breve actualización acerca de los procesos historiográficos y de cartografías urbanas antes de analizar los proyectos atendiendo a las etapas formales descritas respectivamente por Florescano (2012) y Valencia Palacios (2009).

\section{Historiografía y Cartografías urbanas en el arte contemporáneo.}

Como ciencia, la Historiografía o escritura de la Historia oficial se despliega en tres fases: la fase documental o de investigación en las fuentes; la fase explicativa-comprensiva, que supone pensar la Historia; y la fase de representación historiadora o escritura narrativa del discurso (Florescano, 2012). Para llevar a cabo la primera fase se utilizan dos tipos de fuentes históricas: la documental, que pretende construir la Historia de la manera más objetiva posible, y la del recuerdo personal, ligado a la subjetividad y a la reflexión, cuya finalidad es hacer memoria. Esta última tiene como misión dotar de mecanismos a la sociedad para la recuperación de testimonios que puedan contribuir a la relectura de la Historia y al reconocimiento social de los grupos minoritarios. La distinción la explica Crenzel (2010) cuando pone de relieve la diferencia entre hacer memoria como un proceso subjetivo basado en el recuerdo individual o colectivo, y hacer historia, que utiliza la narrativa para hacer comprensible lo que ocurrió en el pasado. Son, por tanto, dos modos distintos de producción de las representaciones y del conocimiento. 
Lapeña Gallego, Gloria; Ortuño Mengual, Pedro

El archivo de historias en la construcción de la Historia: la obra cartográfica de Rogelio López Cuenca

III CONGRESO INTERNACIONAL DE INVESTIGACIÓN EN ARTES VISUALES :: ANIAV $2017:$ : GLOCAL [codificar, mediar, transformar, vivir] http://dx.doi.org/10.4995/ANIAV.2017.5736

Por otra parte, el mapa de una ciudad o representación esquemática a escala de la planta de los edificios y el trazado de las calles, es una herramienta que facilita la localización de los lugares. Además, puede contener otros aspectos sobre las relaciones de los ciudadanos que la habitan en el momento actual, así como representaciones visuales de la Historia y la memoria individual y colectiva de diferentes temporalidades. Cartografiar una ciudad desde este punto de vista consiste en reflejar la complejidad heterogénea de la ciudad fragmentada e imprevisible. Valencia Palacios (2009) propone un procedimiento cartográfico en tres pasos para el registro y representación del espacio urbano contemporáneo. En primer lugar, es necesario definir los imaginarios del espacio, o dimensión social de la ciudad que da sentido a la práctica de habitar. Su representación cartográfica contribuye a la visibilización de lo que regularmente no se representa. El segundo eslabón del procedimiento cartográfico es la huella o registro de los hechos urbanos, cuya pista es necesario seguir una vez trazado el imaginario. Hay varias formas de recolección de huellas, como la entrevista, la toma de fotografías y la colección de objetos representativos. Por último, el mapa es el resultado del procesamiento de la información acumulada en el registro de las huellas. Se convierte así en conocimiento, un producto simbólico resultado de la interpretación, aunque nunca igualará a la experiencia del territorio (Maderuelo, 1990).

Por tanto, hacer memoria como expansión de la Historia y cartografiar la ciudad, sigue un proceso similar que podemos resumir en tres pasos (documentación, organización del material y representación), y que da cabida a otros colectivos más allá del historiador y del geógrafo, como el artista.

\section{Proyectos historio-cartográficos urbanos de Rogelio López Cuenca.}

Rogelio López Cuenca (Málaga, 1959) artista visual, filólogo y poeta, produce una obra de carácter político en la que combina imágenes cotidianas con elementos propios de la Literatura para poner en evidencia otras historias no hegemónicas y los lugares no institucionales de las ciudades. Sus proyectos de arte público dan visibilidad a las identidades, las memorias colectivas, los movimientos migratorios, los límites geográficos y las fronteras, para hacer frente a las manipulaciones de la Historia y del mapa como formas de control social y del territorio respectivamente. Estos dos aspectos de su producción, la intervención en el espacio urbano y el contra-mapa frente a la Historia institucional y al mapa militar, lo sitúan en los márgenes de las Ciencias Sociales.

Los cuatro proyectos de López Cuenca que nos ocupan en este trabajo se refieren a cuatro ciudades concretas: Roma (Mappa di Roma, Roma 77, 2006-07), Mataró (El revés de la trama, 2008), México (No/W/Here. Ciudad de México, 2010) y Valencia (Mapa de Valencia/Polivalencias, 2015-16). Se trata de trabajos colaborativos en los que intervienen investigadores de diversa índole, y en los que se crean archivos de historias locales (que con frecuencia se contemplan de manera aislada) puestas en relación con lo global mediante una visión transversal. El procedimiento creativo cumple las tres fases planteadas para la Historiografía y las cartografías urbanas.

\section{Recopilación de datos.}

La primera fase, correspondiente a la documentación y a la delimitación de los imaginarios, es llevada a cabo por colectivos de artistas, profesionales de diferente índole y colaboradores en general con el ánimo de participar en la construcción de una memoria colectiva. Apreciamos que los cuatro proyectos tienen un origen similar en cuanto que participación colaborativa. Las fuentes utilizadas para la documentación son de diferente índole. Desde recursos bibliográficos escritos (como periódicos, revistas, vídeos, imágenes de publicidad y eslóganes) hasta entrevistas e investigación directa a pie de calle.

Así, el origen de El revés de la trama es el resultado de un taller, Derrotas alternativas: Now/here Mataró (2008), en el que un grupo de trabajo investiga junto al artista malagueño sobre los discursos subterráneos o subalternos de la ciudad de Mataró y su relación con los procesos globales. Conceptos como "inmigración", "esclavitud", "lo exótico", "poder" y "violencia sobre los cuerpos" van tejiendo historias reales en torno a la industria textil de Mataró, origen de todo este fenómeno de movimientos humanos.

Mappa di Roma surge también a partir de un proyecto, el Seminario di Ricerca e Formazione de la Fondazione Baruchello que en 2003 toma una iniciativa abierta dirigida a jóvenes artistas y académicos procedentes de todo el mundo. Se organizan actividades durante un periodo de tres meses y finalmente se presentan los resultados del trabajo de un grupo de veinticinco participantes por cada edición dirigida por Emilio Fantin y Cesare Pietroiusti (2003-04), Mauro Folci (2005) Gianfranco Baruchello (2006) y, finalmente, López Cuenca (2006-07). No/W/Here.

Ciudad de México (2010) es un ensayo de altercartografía llevado a cabo en el Centro Cultural de España en México durante las celebraciones del Bicentenario de la Independencia de México y el Centenario de la Revolución. Al igual que los anteriores, es el resultado de un trabajo colaborativo en talleres dirigidos por López Cuenca.

El más reciente, Mapa de Valencia/Polivalencias, es un proyecto concebido para la exposición Radical Geographics (Institut Valencià d'Art Modern, octubre 2015-enero 2016). El trabajo colectivo parte del workshop No/W/Here: Valencia (Facultad de Bellas Artes, Universitat Politècnica de Valencia, abril de 2015). 
Lapeña Gallego, Gloria; Ortuño Mengual, Pedro

El archivo de historias en la construcción de la Historia: la obra cartográfica de Rogelio López Cuenca

III CONGRESO INTERNACIONAL DE INVESTIGACIÓN EN ARTES VISUALES :: ANIAV 2017 :: GLOCAL [codificar, mediar, transformar, vivir] http://dx.doi.org/10.4995/ANIAV.2017.5736

Pensar la Historia, hacer memoria.

Una segunda fase del proceso se corresponde con la fase explicativa o comprensiva, la de pensar la Historia sin exclusión a partir de las huellas que dejaron las historias locales de la ciudad ocultas por legitimidades simbólicas con fines económicos.

De la ciudad de Valencia se ponen en evidencia algunos tópicos separados en el tiempo, como el movimiento okupa y la acción de los colectivos en defensa del territorio y de los abusos especulativos junto a la historia de la Inquisición; datos como la proporción de género en las instituciones; y música con letra subversiva, como las canciones València, eres una puta de Senior i el Cor Brutal o Mucha policía, poca diversión de Eskorbuto. En Roma se desecha la idea de la "ciudad eterna" y turística para poner de relieve movimientos sociales y políticos incómodos y molestos que tuvieron lugar en torno a 1977, y que fueron censurados por la Historia global de una ciudad compleja. En torno a un tema central que gira alrededor de la industria textil de la ciudad de Mataró, se recopilan todo tipo de textos, imágenes, dibujos y vídeos que tratan aspectos relacionados con las migraciones (incluyendo recortes de periódicos sobre el endurecimiento de las leyes contra la delincuencia y la inmigración ilegal) la esclavitud (el imaginario negro africano sobre el que se tiene una visión positiva a la vez que compasiva) y la mujer en el trabajo (condiciones infrahumanas en trabajos de economía sumergida y sin normas de seguridad). El carácter fragmentario de la ciudad de México se pone de manifiesto por la brecha étnica entre la figura del conquistador y el indígena, sinónimo de pobreza y de lucha contra el poder nacional.

\section{Materialización de los proyectos.}

Por último, la representación del proyecto se materializa en un plano de la ciudad (Ilustración 1). Los tópicos particulares de cada ciudad se enlazan a través de un hilo conductor que recompone la narrativa, pero no de manera lineal y cronológica, sino como una red atemporal que llama la atención sobre la presencia de problemas sociales, marginados y jerarquías arbitrarias presentes en cualquier ciudad, pero ocultos entre la hegemonía y el poder local. Esta fórmula archivística, ya empleada en el proyecto inacabado de Walter Benjamin Libro de los Pasajes, es muy utilizada por los artistas historiadores. Tal y como apunta Guasch (2005) "busca transformar el material histórico oculto, fragmentario o marginal en un hecho físico y espacial". Se trata de establecer redes y asociaciones similares a las del Atlas Mnemosyne del historiador de arte Aby Warburg, que clasifica imágenes fotográficas heterogéneas atendiendo a los pequeños detalles que perviven al margen de las épocas, formas y estilos (Santa Ana, 2010).

Mientras que en Roma 77 los archivos se refieren a hechos históricos acaecidos en Roma en torno a 1977, tales como la muerte de Pasolini (1975) y el secuestro y muerte de Aldo Moro (1978); los dieciséis archivos de El revés de la trama se organizan en torno a la industria textil de Mataró, la fábrica, el trabajo obrero, la esclavitud y la migración; No/W/Here. Ciudad de México (2010) es un ensayo de altercartografía que habla de historias al margen de las efemérides, del panteón de los héroes y de las cartografías oficiales que han quedado en las afueras y en los intersticios de la ciudad; la manera de superponer los archivos de Polivalencias (Valencia 2015-16) es un video editado por Elo Vega en el que se mezclan imágenes institucionales de proyectos urbanísticos con otras historias de Valencia, todas ellas, como apunta el propio artista, "increíbles pero ciertas".

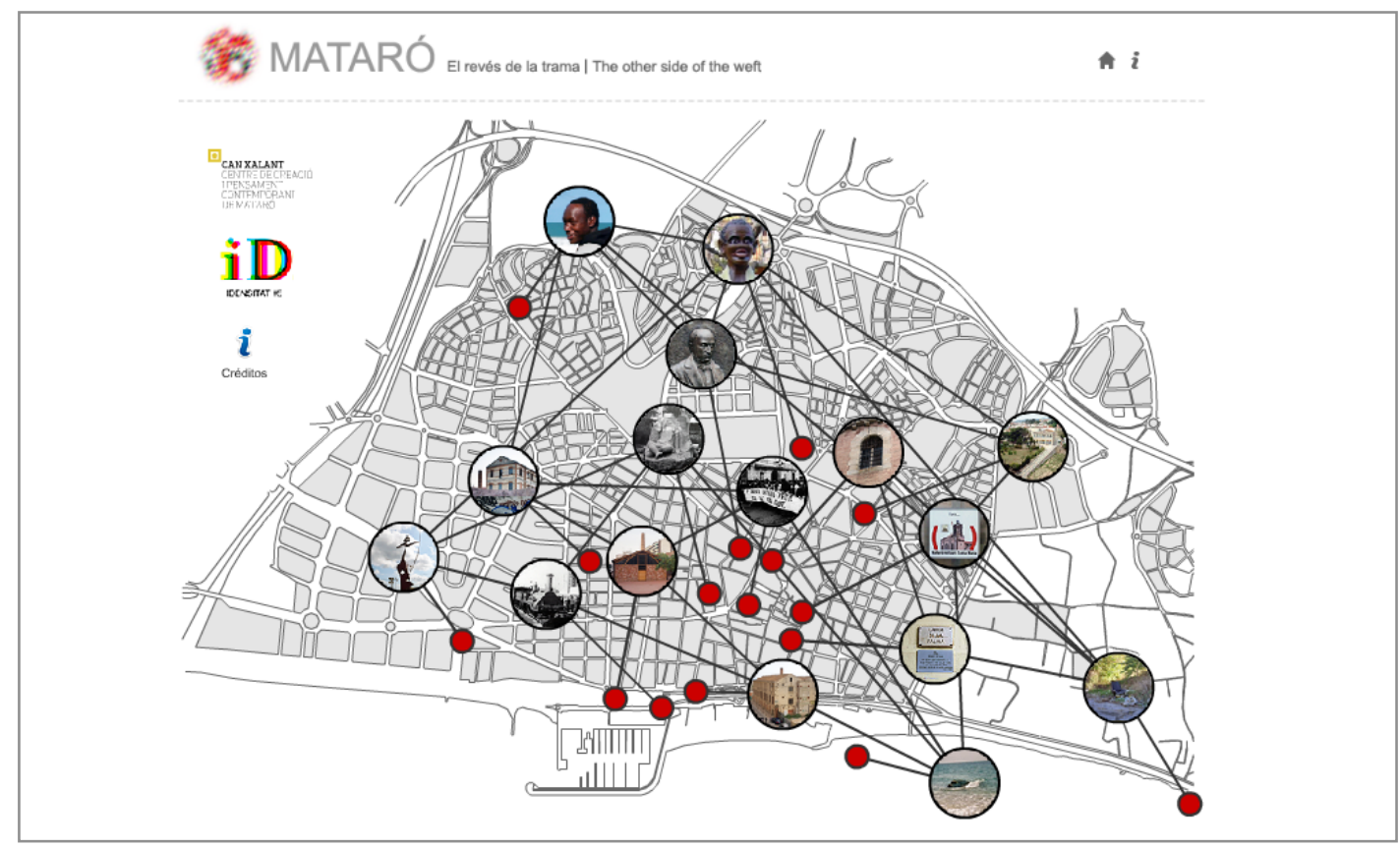

ANIAV Asociación Nacional de Investigación en Artes Visuales

This work is licensed under a Creative Commons Attribution-NonCommercial-NoDerivatives 4.0 International License (CC BY-NC-ND 4.0) 

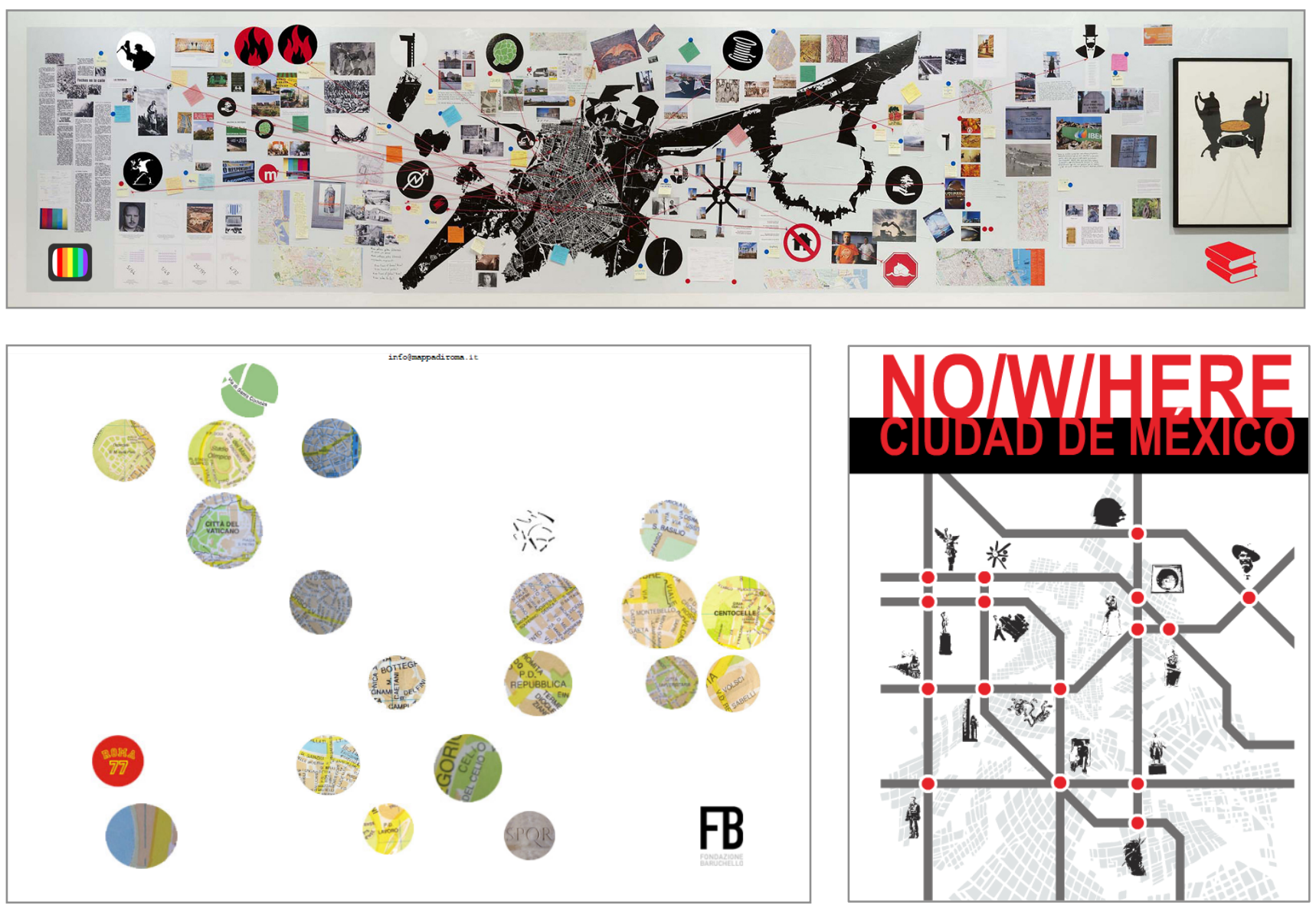

Ilustración 1. Presentación cartográfica de los proyectos de Rogelio López Cuenca: Derrotas alternativas: Now/here Mataró (2008). http://www.mapademataro.net/ Polivalencias (Valencia 2015-16). http://mapadevalencia.lopezcuenca.com/ Mappa di Roma (Roma, 2006-07). http://www.mappadiroma.it/ No/w/here. Ciudad de México (México, 2010). http://www.mapademexico.org/

Conclusiones.

La ciudad como receptáculo de memoria alberga historias cotidianas olvidadas por la Historia hegemónica. Algunos artistas contemporáneos como Rogelio López Cuenca las recogen en forma de archivo mediante un proceso de indagación muy similar al del historiador y el cartógrafo urbano. Tiene como resultado final la presentación de un archivo insertado en un altermapa, con cabida para imaginarios sociales locales, minorías culturales y religiosas que habitan el mismo espacio que los héroes. Los cuatro proyectos de López Cuenca presentados en este estudio muestran historias fragmentadas de ciudades que hablan de temas pertenecientes a diferentes temporalidades y que acaban construyendo la Historia global de la ciudad habitada. 
Lapeña Gallego, Gloria; Ortuño Mengual, Pedro

El archivo de historias en la construcción de la Historia: la obra cartográfica de Rogelio López Cuenca

III CONGRESO INTERNACIONAL DE INVESTIGACIÓN EN ARTES VISUALES :: ANIAV 2017 :: GLOCAL [codificar, mediar, transformar, vivir] http://dx.doi.org/10.4995/ANIAV.2017.5736

\section{FUENTES REFERENCIALES.}

CRENZEL, E. 2010. Historia y memoria: Reflexiones desde la investigación. Aletheia, 1(1), pp. 1-13. ISSN 2145-0366.

FLORESCANO, E. 2012. Pilares de la historiografía. Revista de la Universidad de Méjico, 103, pp. 9-16. ISSN 0185-1330.

GUASCH, A. M. 2005. Los lugares de la memoria: el arte de archivar y recordar. Matèria. Revista internacional d'Art, 5, pp. $157-183$.

ISSN 1579-2641

MADERUELO, J. 1990. El Espacio Raptado: Interferencias entre arquitectura y escultura. Madrid: Biblioteca Mondadori. ISBN 978-84397-1678-5.

SANTA ANA, M. 2010. Pensar con imágenes. Periódico El País. Sección Babelia. Disponible en:

https://ciervalengua.files.wordpress.com/2010/06/20100501elpbab_124.pdf

VALENCIA PALACIOS, M. 2009. Cartografías urbanas. Imaginarios, huellas, mapas. Revista electrónica Diseño Urbano y Paisaje, 16, 117. ISSN 0717-9758. Disponible en: http://fidonline.ucentral.cl/pdf/cartografias_urbanas_dt3.pdf

Páginas web de los Proyectos de ROGELIO LÓPEZ CUENCA:

Derrotas alternativas: Now/here Mataró (2008). http://www.mapademataro.net/

Mappa di Roma (Roma, 2006-07). http://www.mappadiroma.it/

No/w/here. Ciudad de México (México, 2010). http://www.mapademexico.org/

Polivalencias (Valencia 2015-16). http://mapadevalencia.lopezcuenca.com/ 